\title{
Research on the Enterprise Management and Employee Incentive Mechanism under the Environment of Enterprise Social Networks
}

\author{
Wang Xia ${ }^{1}$ \\ ${ }^{1}$ Xi'an International University, \\ Xi'an 710077,China
}

\begin{abstract}
In this paper, we conduct research on the enterprise management and the related employee incentive mechanism under the environment of enterprise social networks. As the sharp change in the environment, the enterprise how to win the competitive advantage for a long time which caused many strategic management thinking, to promote the new development of the theory of the strategic management. Our designed mechanism will enhance the management activities and promote the general value of the employees which has significant meanings.
\end{abstract}

Keywords: Enterprise Management; Employee Incentive; Enterprise Social Networks.

\section{Introduction}

Under the background of global management innovation vigorously, the domestic management also gradually realize that Chinese enterprises on the efficiency of management and the gap between the international advanced enterprises, and leading Chinese companies to join the management innovation and the wave of change, not only devoted to study the business process reengineering, divisional system, lean production, modern assembly line and other advanced management idea and method, and try to build a new management mode. With the acceleration of global economic integration, the uncertainty of business environment growing, industry increasingly blurred border, the stability of the industrial structure of declining, the competitive advantage of enterprises is increasingly unsustainable. As the sharp change in the environment, the enterprise how to win the competitive advantage for a long time which caused many strategic management thinking, to promote the new development of the theory of strategic management. In with China's accession to the WTO, part of the enterprises in our country are open to foreign investment, with high technical content, organization scale, management idea of the new foreign capital enterprise, China needs to have a batch of large national enterprises to compete with foreign companies, and these enterprises must have the enterprise development strategy theory as the guidance. View of new institutionalism in organization theory, decision-making system background in individuals, enterprises and the external level, profoundly influenced the choice of resources and sustainable competitive advantage. New institutionalism emphasizes the role of the institutional environment, the key is to explain the organization form of convergence, regarded the environment as composed of concept, culture, religion, system synthesis. In new institutionalism theory, the organization is still a relatively passive and more influenced by the environment, focus on the organization of the system and structure, and as the organization form of organization domain rather than the individual characteristics. The system background here refers to the rules, norms and beliefs of the sling around the economic activity [1].

In the process of enterprise's survival and development, played a key role, enterprise human quality is the first condition of enterprise survival and development. But in the face of increased environmental restrictions, in the past, many of the enterprises to improve effectiveness and efficiency of the traditional methods have 
failed. In the modern enterprise employees incentive problems are as follows. (1) Incentives to form a single. In reality, some modern companies do not always need to consider the employee's heart. When incentives regardless of level, regardless of time, to give material incentives, form a single, incentive didn't play a proper role, incentive effect is not satisfactory. (2) Performance evaluation and rewards and punishment system. By the traditional effective application of the assessment results to grasp the operation of the enterprise, arouse the enthusiasm of staff is one of the purposes of the modern enterprise performance evaluation. But in the present modern enterprise performance evaluation system, there is a big problem. (3) Lack of enterprise culture construction. Shortage of enterprise managers understanding of corporate culture, leadership is short-sighted, shortcuts, and there is no clear goal of enterprise and the basic beliefs, not form a common values. (4) Lack of evaluation based on incentive. Some of the modern enterprise management system is not sound, the working standard is not clear, which is difficult to employees on a reasonable performance. (5) Incentive mechanism is not perfect, the lack of system planning. Modern enterprise culture construction is still in its infancy, less attention to corporate culture, in some small and medium-sized enterprises, operators focus on enterprise's production and operation, neglect the cultivation of human resources, some even don't have the corresponding incentive mechanism. (6) The lack of staff career planning. Many modern enterprises rarely consider young employee career development, management pay less attention to employee promotion space design. (7) The insufficient recognition of staff training, training funds cannot be guaranteed. Company for fear of a lot of money on the investment on the training, many employees due to lack of proper loyalty to the company, in its ability to mature after leaving the company, lead to the result of the company sets the goods [2]. So, a lot of operators and employees simply employment relationship, is not willing to spend money on training for employees which is not willing to invest in training talents.

To deal with the mentioned challenges, in this paper, we conduct research on the enterprise management and the related employee incentive mechanism under the environment of enterprise social networks. With the influence of modern information and economic globalization, countries enterprises are faced with the increasingly fierce market competition. To occupies a place in such fierce competition, must strengthen the human resources management, give full play to the talent advantage. Talent is the enterprise strategic target to realize the important guarantee of, improve the enterprise human resources management is the core ability to make the enterprise long term stable development. In the following parts, we will discuss the issues in detail.

\section{Our Designed Management Mechanism}

The Principles of Enterprise Management. It is the best asset of the enterprise. How to make the person use and give full play to the potential of employees, employee has been the important work. Talent into the degree and effect of significantly affects the competitiveness of the enterprises, nowadays most companies perceive this, and take active measures to achieve this goal, use all kinds of incentive methods, such as salary, welfare incentive, equity incentive, job motivation and in the hope of employees incentive is effective which achieved good results [3-4].

At present the construction of the enterprise management system is gradually to the flat direction development, change the traditional way of choose and employ persons, the employee's personal development gradually, staff career planning into motivation, change the traditional management mode, resource allocation in turning to according to the actual situation of enterprise itself, the allocation of 
resources fully and effectively. From the point of view of psychology, human behavior is dominated by the motivation, motivation is caused by the need, behavior is to seek in the direction of the target, and meet the need. When people need not satisfied, will produce a nervous state of mind, to meet a can satisfy the needs of target, the nervous psychology into motivation, and motivation, to the goal, the goal to achieve, needs are met, nervous psychological state can eliminate, subsequently, creates new needs, new motive and behavior. Therefore, managers should understand the needs of the subordinates, grasp what most can motivate subordinates, as well as how these motivational factors play a role, and to study how to produce a particular prompted by the object of management motivation, how to guide them take out all his strength to strive for the realization of a goal, and put these knowledge embodied in management activities, so that they could become effective managers.

Motivation refers to the various factors work together down to inspire and strengthen people's motivation, guide and promote the process of its efforts to accomplish the goal. In the enterprise staff incentive has fully mobilize enthusiasm and creativity of employees, effectively regulating the relationship between organizational goals and personal goals. So establishing perfect incentive system, employee to avoid misunderstanding, realize effective incentive for enterprise human resources management and staff to achieve the goals of enterprise strategy is of great significance.

The Environment of Enterprise Social Networks. Small micro enterprise due to the limited resources, at all stages of growth cannot leave the social network of support. Factors that affect small micro enterprise social network building is very complex, external factors and internal factors will have an effect on the construction of a social network, but due to the external environment of enterprise has a certain homogeneity, and entrepreneurs or entrepreneurial teams for the entire enterprise's creation and growth has irreplaceable importance. Social network is the important way of small micro enterprises access to resources, entrepreneurs can through the network from the external key resources needed to get the business. Behind any firm growth have the characteristic resources as the foundation, whether the resources are tangible or intangible. Certain resources determine the enterprise growth and the basis of a particular competitive advantage, from this perspective can deeply understand the inner motive power of enterprise growth problems. While acknowledging enterprise development cannot leave the nature resources and core competence, for small and medium-sized enterprises, resources, capabilities, and core competitiveness of the play is also important, its growth is inseparable from the support resources, but with large enterprises, the growth of small and medium-sized enterprises in its own trajectory, the basic issue of small and medium-sized enterprise growth often lies not in whether can better play its existing resources, but in how to better more efficiently obtain the resources needed and accumulated in the process of growing.

Since any economic organizations or individuals with certain social relations with the outside world, Mosaic or suspended in by all sorts of relations connecting interwoven into a social network, then, between it and other organizations and individuals in the network through a variety of characteristics of the relationship between coupling, and the different forms of resources through the connection between organizations and individuals in the network flow. The network is not a static thing, it is evolving. Along with the network formation, extension, change, in the network organization has been growing and continuously in accordance with the access to resources. As you can see, this kind of social network theory can better understand the enterprise growth and resource acquisition problem, at the same time, 
due to the small and medium-sized enterprise growth often suffers from serious lack of internal resources, its growth and resource acquisition may be more often depends on the social network, as a result, from the perspective of the construction and evolution of social network on the growth of small and medium-sized enterprises and is particularly important to study the resource acquisition, and has started to have drawn the attention of the increasingly.

The Basic Employee Incentive Mechanism. A person's work performance and the degree of motivated people have a very close relationship. Job performance is equal to the ability to multiply incentive. Therefore, the enterprise employees' incentive in enterprise management plays a very important significance. On the one hand, the motivation is to improve the economic benefit is very important factor. At present a lot of enterprise development, profits, one of the most important reasons is that many business leaders lack of motivation in enterprise management the important role of the deep understanding of. Through incentives can attract the talented person of the ability, knowledge and social talents into enterprise talents, make the value of talent in the enterprise. Companies rely on the wisdom of the talent and creativity the enhanced and developed. On the other hand, the effective incentive can enhance the staff's confidence and ambition, creativity, team spirit, team spirit and the centripetal force. We need to solve the issues when optimizing the current pattern of management. (1) Enterprise performance evaluation system is not perfect. In the process of enterprise management, quite a number of incentives contradictory and conflict are the institutional cause. A set of scientific and effective incentive mechanism is not isolated, should be made to match the enterprise of a series of related system can play a role. (2) Incentive as simple as reward. At present, some managers have no incentive for deep analysis and understanding, there is no accurate grasp of the essence, simply think motivation is to reward, ignore the negative incentives. (3) A single incentive mode and means. The starting point of the incentives will be meet the needs of member, the needs of the part but there are individual differences and dynamic, the needs of employees because of the person different, because of the different. (4) Only emphasis on material incentives, and ignore the spiritual incentive. Material incentive is to point to by means of incentives, encourage employees work. Spirit to stimulate the intrinsic motivation, refers to the invisible spiritual incentives including the general and necessary sense of achievement at work.

The Proposed Solution and Novel Mechanism. Produce huge incentives to achieve company goal. The goal of enterprise which is to rely on people's behavior and people's behavior is driven by enthusiasm. Motivation is to give full play to the enterprise all sorts of factors of production the need of utility. Our proposed solution to the issues could be summarized as the follows. (1) Real continuous multi-level incentive mechanism. Based on enterprises ignore the question of the difference of structure and incentive groups in different periods is recommended, for different types of people should adopt different incentive ways and means. (2) Maintain and optimize the inherent structure of human resource cost and the reasonable proportion. In enterprise management, appropriate to reduce the maintain cost, the proportion of moderate increase incentives cost share of the cost. Maintain cost is mainly human resources base salaries, cost performance for variable pay more reward, the lower base pay can take in the enterprise management practice. (3) When making incentive system should reflect the scientific nature, the enterprise must be systematically collecting and analyzing information related to the incentive, a comprehensive understanding of employees' needs, according to the situation of the constantly changing formulate corresponding policies and measures of science. (4) Improve the scientific 
system of training education which raises the cost of human resources development. Education and training is an important method to motivate employees. With the rapid development of modern science and technology, with the deepening of market competition, the employees to improve their cultural knowledge and business skills will be pressing needs. (5) Implementation of differentiated motivation. The initial thing is based on the understanding of people. Different employees have different requirements as the specific employees at different times and the environment is also has different requirements.

\section{Conclusion}

In this paper, we conduct research on the enterprise management and the related employee incentive mechanism under the environment of enterprise social networks. Incentive is the purpose of in order to fully arouse the enthusiasm of enterprise staff, maximum limit arouse their work potential. Therefore, managers must take into account when making incentive system on the influence factors of enterprise staff's work enthusiasm. Incentive system must embody the principle of fairness, justice and open, a person satisfied with his income by not only depends on its absolute value, comparing history and reality, whether the living standards of personal and social status have got the obvious improvement. By comparing, employees will determine whether or not his pay the fair and just return, will affect the mood and the future of the employees working attitude. Our proposed methodology solves the management issues well which will be more than necessary.

\section{References}

[1] Bao-Ren X I. Research on Incentive Mechanism on New Employee of Enterprise[J]. Business Economy, 2009.

[2] Fan B. Incentive mechanism design for employee knowledge sharing based on principal-agent theory[C]// Logistics Systems and Intelligent Management, 2010 International Conference on. IEEE.

[3] Hong, T. (2011). Research on mechanism and mode of multi-project management in large-scale construction supervision enterprise. Construction Economy.

[4] Li X D, Li X Y. Small and Medium-Sized Textile Enterprise Employee Turnover Motivation Research[J]. International Conference on Industrial Engineering \& Engineering Management, 2013. 